\title{
Taxonomic practices and Indian concerns
}

\author{
Potharaju Venu* and Munivenkatappa Sanjappa
}

Plant taxonomy can become complicated if handled without restraint/caution in floral documentation. Effectively, taxonomic practices provide a procedure/method for naming, reporting (publishing) and subsequent cautious filing of materials in the herbaria. A literature scrutiny provides multiple examples of lack of seriousness and dishonesty in varied areas of taxonomic research. In reporting new species, it is always desired to have an in-house deliberation for opinion, as collective wisdom/expertise helps the authors eliminate any omissions that might appear later in publications. Rediscovery reports from India frequently fail to be relevantly content-spirited. Their reporting requires great prudence and rigorous scrutiny. In this article, the long existing partial knowledge in unisexual plants in a few angiosperm families is discussed. Many a time, irrationally, status judgements (IUCN statuses) are assigned to species with inadequate information on distribution details. Nomenclature and taxonomy should go hand in hand to bring in clarity regarding any taxon and to resolve issues. Naming or struggle for a right name appears to be the priority for a near nonexistent species than for their fresh collections. Issues on naming of plants after one's own masters or relatives to oblige them are also deliberated. Concerns related to herbaria maintenance and failing in the deposition of types and vouchers in herbaria are discussed. The literature without specimen base leads to ambiguity, and spells a debacle in revisionary works and consolidation of floras. Further, there are also apprehensions linked to publishing new combinations based on publications from elsewhere and without having a grasp/judgement of the genera involved. There are also articles concerning lectotypifications undertaken by taxonomists without due enquiry. Such publications may help promote the concerned authors in their careers, but contribute little and generate greater noise in the subject.

Keywords: Explorations, lectotypification, new and rare species, rediscoveries, taxonomic practices.

EXPLORATIONS are an integral part of floral documentation. Novelties are reported/published as plant discoveries when recognized from these gathered materials by taxonomists. These reports generate enthusiasm and excitement as they are supposed to stir/review all the known component species of the genus they belong to for morphological similarities and differences. Such reviews recognize and compare the novelty (or new species) with the known near-similar/allied species. The authors who contribute to such publications remain permanently attached to the taxon (species/infraspecific categories) published. The other outcome of plant explorations, which is often regarded as of auxiliary significance, is the collection of rare species after considerable time periods. Some species stand so rare, they were never known to have been collected after the type collection (a collection of specimen/s

Potharaju Venu lives in the Jade Block, My Home Jewel, Hyderabad 500 048, India; Munivenkatappa Sanjappa is with the Mahatma Gandhi Botanical Garden, University of Agricultural Sciences, GKVK, Bengaluru 560 065, India.

*For correspondence. (e-mail: pvenu.bsi@gmail.com) based on which a species new to science is described; hereafter referred to as type). Quite a few species (majorly endemic ones) might appear with fewer collections and from very limited localities or from narrower geographical boundaries. In certain cases, even the existing single/ couple of collections often bear no flowers, fruits, or both, often with incomplete descriptions and no clear mention of localities. While some go into near oblivion, others are referred in floral documentation based on type material/original publication. Though a good number of rediscovery reports appear annually, still many such species await tracking and localizing through dedicated exploration surveys in specified areas. A great number of these species appear in unresolved status in important plant databases (e.g. www.theplantlist.org) for want of all-inclusive clarity of the material and the name it bears. The case of Mitrephora published by Thothathri and Das ${ }^{1}$ may be taken as an illustrative example of how rediscoveries can help in resolving the status of a species. The authors appeared to be not in full knowledge of Mitrephora andamanica when they described it as new ${ }^{1}$. The type specimen at Calcutta herbarium (CAL) has only 
immature flowers and also with no fruiting material. Since the species remained unreported after the type for almost 50 years, it was placed under 'unresolved' in major plant databases. In a later (re)discovery, this species was sighted in flowering and fruiting from North Andaman Islands, India and is now wholly described ${ }^{2}$. In reporting new species, it is always desired to have an in-house deliberation for opinion, as collective wisdom/expertise help the authors eliminate any omissions that might appear later in publications. Secondly, opinion from concerned experts abroad may change the perceptions of the authors towards collected materials critically. For many reasons, there is a need for meticulous scrutiny of material and thoughtfulness while reporting rediscoveries than while reporting new species. The joy of collection of a rare species lies with not only looking at the living plant in its natural habitat, but getting an opportunity to work with live specimens to improve descriptions. Rediscoveries of such species are cherished by taxonomists and have diverse implications in floral documentation and consolidation. Few publications have appeared in the Indian context with inclusion of rediscovery in the title of the articles but with a different sense from what it is actually envisioned for. Few authors have applied this to some species which are known by limited collections in India, but widely known and distributed in other countries. Ceropegia lucida Wall. (known from India and in Bangladesh, Myanmar, Malaysia and Thailand) and Saussurea andryaloides (DC.) Sch.Bip (China, India and Pakistan) were reported as rediscoveries when they were traced in India after long intervals ${ }^{3,4}$.

\section{Plant discoveries/rediscoveries and consolidation}

New materials prompt reporting of not only species new to science, but new records and extended distributions of many known species. It is not infrequent to describe novelties from the materials already existing in herbaria, but such materials could impose limitations on the part of the describing author variously depending on the group. Typical phrases such as 'flowers/fruits... not known' can be seen in earlier floras (the flora of British India and Provincial floras $)^{5-8}$, which have documented many such novelties based on the limited herbarium materials in different groups. Regrettably, the situation continues to be unchanged in the knowledge status in many such taxa even in lately revised publications, since they are based on available materials and not on field works.

Since 2007, the Botanical Survey of India (BSI) has been compiling/consolidating information on plant discoveries annually and updating the estimated taxa in every group. These figures might not qualify for actual/absolute numbers, since some names get reduced as synonyms in various taxonomic revisions. However, they can be taken as near approximations for different groups. As of 2019, keeping aside review consolidations of different groups, it has been suggested that a total of 18,800 taxa of angiosperms and 82 taxa of gymnosperms are known to be occurring in India ${ }^{9}$. Since rediscoveries were presumed to be already in the accounted enumeration, they had not been primarily considered in the inclusion of yearly publications of Plant Discoveries ${ }^{9}$. The publications on rediscoveries exert a different influence on the floral documentation. Their inclusion in the yearly consolidation reports is desired.

A scrutiny of the herbaria, literature and earlier field surveys indicates that about 250 taxa of vascular plants (angiosperms and pteridophytes) could not be tracked after their type collection. An attempt made recently revealed that 69 taxa of angiosperms are still known only by their type collections ${ }^{10}$. This figure too needs scrutiny, as it is not always certain that all the listed rare species stand as good species in the course of enquiry and review.

\section{The relevance of specimens and issues in depositions and exchange}

In ideal situations, taxonomists' work locations swing between herbaria (for dry specimens), field exploration areas (for fresh collections) and libraries/digital libraries for materials and the literature (www.biodiversitylibrary.org; www.botanicus.org; www.bnf.fr/en/gallica-bnf-digitallibrary; www.kew.org/herbcat; www.mnhn.fr/en/collections, etc.). Good taxonomists are expected to present their findings keeping up this link coherently and effectively. Unfortunately, many floras which had appeared in recent years do not maintain specimen base or the sanctity of depositing the vouchers in recognized herbaria to uphold this connectivity. With no mandatory checks in specimen depositions, we have taxonomists providing multiple floras shuffling the data from one flora to another and vice versa (State floras $\rightleftharpoons$ district floras) in no time. For erstwhile Andhra Pradesh alone, we have about 30 floras (districts/specific areas/protected areas), which is in fact uncalled for. The malady of this publishing went to such an extent that when a newer state was carved out (Telangana), its flora appeared instantly, which is primarily based on the flora of United Andhra Pradesh. They are more fictitious than holding any authentic and serious taxonomic content. All observations/comments made out in floras are supposed to be tied lastingly in the deposited specimens and are proved essential for clarifying any misinterpretations and misidentifications. Many cytological, anatomical, phytochemical and embryological studies happen without proper deposition of vouchers and as a result, there will never be a scope to verify exactly on what materials they worked on.

The apathetic attitude even extends in depositing the types by some authors, that may lead to nomenclatural and taxonomic ambiguities in described novelties ${ }^{11}$. The 
presence/absence of type materials of the names of new taxa published from India during 1990-2004 had gone into serious review ${ }^{12-15}$. These reviews had covered journals such as Rheedea, Nordic Journal of Botany, Bulletin of the Botanical Survey of India, Candollea, Indian Forester, Indian Journal of Forestry and the Journal of Economic and Taxonomic Botany to give an inclusive analysis of the new taxa published for the said period. A consolidated account on the presence/absence of type materials was presented in four articles. Numerous inconsistencies between the data in the protologues and what is written on the original labels of type specimens were presented in these articles.

The analysis suggested that the types of 124 names are available at the respective herbarium/herbaria as stated in the protologues; for 50 names either holotype/isotype or paratype is found in the stated herbaria, but not all the types and no types could be located for 115 names. This implies that nearly $40 \%$ of the names published for the said period do not have specimens readily available for scrutiny. The omissions are found to be more with novelties published in the Journal of Economic and Taxonomy Botany. We may face an additional agony when fragmentary materials are deposited as types, which do not serve the purpose of application of the name. These include Cycas sainathii (type: India, R. C. Srivastava 201, CAL), C. darshii (type: R. C. Srivastava 202, CAL) and $C$. pschannae (type: India, R. C. Srivastava, 19, CAL) ${ }^{16-18}$. When the original material is demonstrably ambiguous or insufficient as in such cases, an additional and clarifying type requires to be designated as an epitype ${ }^{19}$. But even when protologues turn out to be ambiguous, the job of the revisioner would become more difficult.

There shall be further boom in the publication of new species in India with no holds bar, as Art. 29 of the ICN (International Code of Nomenclature for algae, fungi and plants, and hereafter referred to as 'Code') has approved electronic publication of new species by PDF in an on-line publication with an ISSN or ISBN (with effective date: 1 January 2013) as valid ${ }^{19}$. We will create a real mess if we continue to ignore the deposition of types.

It is relevant to state that Section 39 subsection (3), of the Biodiversity Act 2002 mandates that 'Any new taxon discovered by any person shall notify and deposit the voucher specimens (types) to the recognized national repositories or institutions designated for this purpose ${ }^{20}$. Regrettably, type specimens of many recently described plant species have been shown to be deposited in herbaria outside India and not in the designated Indian repositories. This is in fact a violation of the stated Act. As a consequence, our physical access to specimens becomes difficult and the scrutiny and authentication of new materials will be compounded. Some justify specimen depositions in herbaria abroad by mentioning that our repositories are not good enough to maintain them safely and securely. The Indian climate with high humidity, at least in some herbaria, poses problems of specimen maintenance. However, the Ministry of Environment, Forests and Climate Change, Government of India, has provided fairly sufficient budget and manpower to maintain all the 13 herbaria including the Central National Herbarium at Howrah. The maintenance, safety and security of specimens in our national and other regional herbaria is evident from the fact that the oldest collections made in 1690 and 1797 at CAL and MH respectively, are still well-preserved $^{21}$. The regulation of the National Biodiversity Authority (NBA) even extends to collaborative research projects involving exchange of dead or preserved specimen(s). The guidelines suggest that it should be done with the competent approval of concerned Government Departments/Ministries. The current policy of the National Biodiversity Authority (NBA) was criticized for ruthlessly imposing rules framed to regulate commercial exploitation of biological resources on fundamental research $^{22}$. NBA by itself cannot handle biological resources without being actively advised by both Botanical and Zoological Surveys and the Institute of Microbial Technology of the country. The Directors of these Surveys and repositories should have greater role than being mere ex-officio members in expert committees to serve the mandates of all three organizations and to ensure that there are no hurdles among these organizations. Taxonomists already have problems in obtaining permissions for field explorations from the State Forest Departments ${ }^{23}$.

\section{Herbaria maintenance}

Specimens in herbaria maintain a necessary link with the floras and other taxonomic works published in the past, and without well-preserved herbarium material and image database, we cannot be sure of maintaining scientifically reliable identification of plants. Herbaria require periodic maintenance, particularly in humid tropical situations for their continued survival. Many specimens represent extremely valuable collections. Despite most national repositories (herbaria) being air-conditioned, specimens are exposed to high humidity during rainy season. A lot of effort is needed in establishing, building and maintaining these herbaria. Also, herbaria linked to universities and non-governmental organizations have no facilities to maintain collections, and they require support in terms of human resources and capital infrastructure. Fortunately, the herbaria of BSI have curatorial staff for taking care of specimens on a regular basis. The Central National Herbarium of BSI at Howrah (CAL) has a maintenance expenditure (annual fumigation, annual maintenance and service charges for central air-conditioning and electricity charges) amounting to Rs $5(\approx 0.06$ Euros) per specimen per year. This does not include the salaries of personnel involved in maintenance. The annual earnings from the technical services provided by CAL are significantly less 
than the expenditure needed for maintenance of the herbarium $^{24}$.

\section{Rediscoveries and implications on the literature}

In publishing rediscoveries (of rare species), one of the four possibilities happens. The explorers who come across such rare materials might rightly and effectively fix the identity of the rare species. Such species once rediscovered, get ascertained in the literature and would ascend as accepted names in all floras, including plant databases (which were till then in unresolved status for want of further material evidence). In case the original reported novelty itself is flawed and with no definitive and tenable diagnostics from the ascribed allied species, it gets reduced as a synonym. It decides once for all the existence/nonexistence of the reported novelty under reference and helps in cleansing the literature from such pseudo species. In some instances, the failure of recognition of published rare species leads to publishing them as new species. It could happen for two reasons; one, by failing to take stock of the rare species rightly and two, due to lack of adequate material for comparison. There are also occasions of publication of new species based on mis-identification of an otherwise well-established species. If not corrected on time, they remain as rare species waiting for rediscoveries. Certain rare species are in such a situation that both the type and the protologue may prove to be inadequate while naming them. In such circumstances, the authors with circumstantial evidence and honesty can think of designating an epitype from the newer collections to bring in clarity on the said rare species. Rare species truly deserve introductions in the botanical gardens due to the fact that some reported rediscovered species went again into obscurity ${ }^{25}$. All regional centres of BSI maintain databases of such species which have been flourishing in their gardens. All these actions can be done with greater objectivity and due justifications. Any errors or lapses in these exercises may add further burden in species accounting and flora writings. Few case studies are presented here to elaborate our viewpoints stated above.

\section{Lacunae in reporting rediscoveries}

More often, rediscovery reports from India fail to be relevantly content-spirited. They take a fixed approach and the presentations in reporting do not change as necessitated by specific and exclusive situations. What should be cardinal in such presentations is to focus on diagnostics, how it was the rediscovered species under reference and not others, and also tracing possible reasons for not being reported after type collection. Further, the prospective authors are supposed to examine the literature (particularly where it was included based on type material) and whether the species under reference was included based on a true understanding of it or as a 'mechanical inclusion'. In such works, the identification keys are to be examined which might help in characterizing the species rightly and vividly. This should go without any deviation from the concept of the original author and should be done in the light of type material and protologue. Also the habitats and distributions of the species under reference as well those of the allied species aid in the analysis. Unfortunately, in few rediscovery reports, it was observed that protologues are copied as such to reassure readers what the authors collected is the claimed rare species under reference and, with no honesty and scrutiny of their collected material. In a recently reported rediscovery (Begonia tessaricarpa C.B. Clarke), after a lapse of century of the type collection, the authors unpredictably state that this species is widely utilized for making 'chatni' and as a leech guard $^{26}$. This might be true, but such declarations are without any sensible explanations on how a species with popular recognition among people escaped plant collectors (after the type collections) for such a long period. Rediscoveries are to be taken more seriously by taxonomists as they could account for 'free names' that add certainty to their continued existence. Further, their material and the associated publication become a practical basis in authenticating collections of this taxon thereafter.

Many a times, irrationally, the IUCN (International Union for Conservation of Nature) status judgements are assigned to species with inadequate information on distribution details ${ }^{27}$. Effective assessments happen from sizable high-quality data on species biology, abundance, distribution and population growth rates, and many such criteria. Usually, taxonomists are neither trained nor in a position to undertake detailed quantitative sampling to generate such data used in this assessment. Customarily, a taxonomist's appraisal of a species spread is limited to designating a species as rare, frequent, less common or more common based on his/her field experience. They might show interest in quantification in case of highly localized habitat-specific trees/shrubs and herbs with limited individuals as a separate study, but not as an integral to core explorations. The compulsive guidelines of many journals drive taxonomists to designate status for new as well rediscovered species. There is no rationality to such insistence. Such assigned statuses have no valued purpose in the Indian context. Status assessments made during 1980s with no numerical support but with pragmatic objectivity have demonstrated that they are fairly useful to focus on threatened species of the country ${ }^{28,29}$.

\section{The naming of species}

The plant names given through binomials consist of two parts: the generic name and a specific epithet. The naming is done by the author/discoverer in accordance with the 
very morphological features of the species, since the name has a bearing with its features and thereby its relationships with other species. The name is also regulated by the Code. There is an impression (and valid to some extent) that taxonomists quite frequently name the taxa after their superiors to oblige them. Many nontaxonomists have mockingly called taxonomists as taxa-namists ${ }^{30-32}$. Further, they have suggested that the specific epithet can be a characteristic feature of the species (so as to remember it easily and identify in the field), or the name of the locality where it was first found (so as to know type locality readily and conserve it). Such suggestions might be right, but their reasoning seems to be on mistaken grounds. A species in its entirety cannot be visualized in a name literally. Polynomial naming for species with near-similar intent (prior to binomials) got defeated as they proved unwieldy in usage. An appropriate reply came from a taxonomist on points raised by these critics ${ }^{33}$. The generic name is the first word and when used in the binomial, it imbibes the generic characterization of the said genus while the second word, the specific epithet, makes it distinct from the other known species of that genus. It is pertinent to state here that a genus holds a group of species that are closely related through common decent. Thus the generic name and the specific epithet together build a concept for a species. By the given binomial, a person conversant with botany can know the family, order and other hierarchical groups as these are built by similarities and distinctions. Undeniably, a few taxonomists resort to please their superiors by naming 'new species' after them. Quite often, these are not truly new and finally get reduced as synonyms, encumbering the taxonomy with avoidable name nonsense.

\section{Issues in recognitions}

A few taxonomists tend to be biased once they build/form opinion on a material. Hajra et al. ${ }^{34}$ published a new genus with a solitary species in the Scrophulariaceae, Hoshiarpuria minutiflora Hajra, Daniel \& Philcox from India (holotypus CAL; isotypii BSD, K). In a short span, the authors realized that the plant is in fact Rotala mexicana Cham. \& Schltdl, a common marshy weed in the family, Lythraceae. Realizing the error, they debunked Hoshiarpuria in two separate communications ${ }^{35,36}$.

The classical case of misreporting of a new genus based on a single species happened based on mixed-up mounting of two different species by van Steenis ${ }^{37}$. He erected Papilionopsis (Leguminosae), on the basis of a single species, $P$. stylidioides Steenis, and concluded that it occupied an isolated position with a basal rosette of leaves but with the inflorescence bearing resemblence with the tribe Galegeae. The holotype of $P$. stylidioides was examined by Verdcourt ${ }^{38}$, who found that the specimen (Bergman 287, Swart Valley, Kadubaka, Papua New
Guinea, 25 March 1958) comprised of a mixture of foliage of Burmannia disticha L. (Burmanniaceae) mounted with an inflorescence of Desmodium repandum Vahl (Leguminosae), which appeared to represent the foliage and flowers of a single plant. Finally, both the genus and its type species got exposed and rejected.

A new species of Crotalaria-Crotalaria nallamalayana (L. Rasingam \& M. Sankara Rao 3715; holotype BSID, isotypes CAL) was described from the Nallamala forest, Telangana, India ${ }^{39}$. It was claimed to be allied to C. orixensis Rottl. ex Willd. and C. senegalensis (Pers.) DC., but differed from them in leaf, stipule, bract and floral characters. The diagnosis of the stated novelty was erroneous in ignoring three important features concerning the number of flowers in the axils of each bract (two nos), condition of the stamens (didelphous) and shape of the anthers (uniform). These were the features of Pycnospora lutescens Schindl. (Leguminosae : Papilionoidea : Desmodieae) that has wider distribution and was never shown to be exhibited in Crotalaria. C. nallamalayana has now got reduced as a synonym of Pycnospora lutescens $^{40}$.

If the novelty and its characterization is erected based on certain insignificant features, they should be reduced as synonyms of other appropriate species. The said synonymy removes the supposed distinct existence of certain species which were once perceived as new. Ellis ${ }^{41}$ described a new species, Andrographis nallamalayana J.L. Ellis based on his collections from Ahobilam and Chellama of Kurnool district, Andhra Pradesh. He distinguished it from A. beddomei C.B. Clarke by its low decumbent herbaceous habit, the inflorescence, both axillary and terminal, the longer calyx lobes and the plants drying dark green or black. A. nallamalayana was treated for a long time as a strict endemic of Nallamalais. Gnanasekaran et $a l^{42}$ rightly argued that $A$. nallamalayana is conspecific with $A$. beddomei C.B. Clarke (1884) and therefore merged it with the latter. For many years between 1967 and 2012, what was truly A. beddomei had gone in the name of $A$. nallamalayana in various floras, while the former as a rare species. A near similar history can be seen with Strobilanthes hallbergiii, so far considered rare, which is genuinely conspecific to $S$. callosa.

\section{Material evidence and the focus on names}

Nomenclature and taxonomy should go hand in hand to bring in clarity of any taxon and to resolve issues. Nonetheless, naming appears to be for namesake if a near nonexistent species is in focus for a correct name. Many such species exist in the Indian literature, but we present the case of one endemic species, Acilepis nayarii (Uniyal) H. Rob. \& Skvarla, as named now. This was originally built on a manuscript name of Beddome, Vernonia recurva, of his own collection from Anamalai hills, Tamil Nadu. It 
was validated by $\mathrm{S}$. Moore as $V$. recurva Bedd. ex $\mathrm{S}$. Moore. Since this was realized as a later homonym (nonGleason, 1906), it was given a new name, Vernonia nayarii Uniyal $^{43}$. In a revision it was transferred to Acilepis as $A$. nayarii based on pollen features ${ }^{44}$. The parody is that this is a near extinct species with a solo type specimen not traced till date. The priority of taxonomists should have been its fresh collections, and not looking for a right name. All these errors of recognitions and corrections leave a burden on the literature with additional synonymy and beat the very purpose of knowing one species by one name universally.

\section{Issues with unisexuality in some genera and families}

The problem of incomplete knowledge spreads in unisexual plants in few angiosperm families. The Code does not prevent publishing a new taxon if one wants to describe it based on only male or female material that he/she had discovered. Pycnarrhena pleniflora Miers ex Hook. f. \& Thomson $(1855=$ Albertisia mecistophylla (Miers) Forman) and Stephania andamanica Diels (1910), both of Menispermaceae, are represented by male plants and, female plants/flowers are not known in both these species till date ${ }^{45}$. Similar issues are also found in some species of Euphorbiaceae. Female flowers are not seen in Claoxylon longipetiolatum Kurz (1873), Drypetes porteri (Gamble) Pax \& K. Hoffm. (1922), D. confertiflora (Hook.f.) Pax \& K. Hoffm. (1922) and Macaranga gamblei Hook.f. (1887). On the other hand, male flowers are not known in Cleistanthus patulus (Roxb.) Mull.Arg. (1866), C. travancorensis Jabl. (1915), Dalechampia stenoloba Sunderaragh. \& B.G. Kulak. (1980), Mallotus leucocarpus (Kurz) Airyshaw (1873) and Leptopus emicans (Dunn) Pojark (1960) ${ }^{46}$. The list is not exhaustive, but illustrative. These species remain incompletely known till date and continue to evade plant explorers for fresh collections for good number of years. It is tricky in some of the dioecious species mentioned above, to fix complementary male/female materials, since it is difficult to know how similar/dissimilar they are from their counterparts. Also, we have no way to study their reproductive complementarity in the limited exploration schedules.

This unisexuality in plants poses complementary issues in typifications. Venkat Ramana et $a l .{ }^{47}$ had encountered a problem while reviewing and in the application of names of Indian cycads. Since these are unisexual plants, designation of holotype was done with reference to either male or female plants. The Code does not give any provision to include both male and female specimens as holotype (though mounted on same sheet), since there is rationale in maintaining the sanctity attached to a single gathering in designation of the holotype. On the contrary, the author of the name acknowledges his/her basis of de- scription on both male and female specimens. Can we afford such visible inadequacy in type of the name when it requires a review? But in the ambit of the Code, the authors can designate one as holotype and the other as paratype since the collections do not come under a single gathering. We can make an effort to add paratype designations to supplement and support the existing names. This can even be applied to unisexual species of angiosperm families.

\section{Concerns on typifications and new combinations}

There is a growing trend in publishing lectotypifications of many Indian species. Typifications are essentially designating typical or reference specimens and the chosen specimen typifies individuals belonging to that species. If (original authors) the author/s of a discovered species fail to designate a holotype, others can do so by selecting one from the original material as lectotype. Ample enquiry and expertise are required in lectotypifications. Primarily, it should be done in the light of good understanding of the group concerned. Additionally, one should have knowledge on the varied histories of collections/work locations of the taxonomists who handled the said group. Indications in the form of manuscript notes, annotations, rough sketches and epithets such as typicus, genuinus on herbarium sheets provide support in the appropriate designation of lectotypes. Preferably, lectotypifications should happen in the revisionary works as an integral to the final consolidation and presentation of the group. Researchers should be capable of holding onto the abovestated threads to take decisions on lectotype from the original materials. The authors who intend to publish on lectotypifications selectively chose narrow endemics and designate lectotypes from two or three syntypes they are aware. Many of these appear to be inconsequential as they fail to present conceivable arguments and need enquiry in the designation. This can be avoided in general floras, but regrettably, in a recently published book on Valmiki Tiger Reserve ${ }^{48}$, lectotype designations for a staggering 420 diverse species were presented. Many stray publications on lectotypifications which have appeared in the last couple of years are mainly due to accessibility of type images of Indian species deposited in European herbaria through image databases, and never based on critical review required in this exercise. Incidentally, some of these lectotypifications may prove to be valid, but perfunctory selections should be avoided as they often lead to future confusions and further corrections. This is truly a 'syndrome' among a few Indian taxonomists.

Another issue relates to publications of new combinations by a few authors. In a recent phylogenetic reconstruction, many African Brachystelma species were brought under Ceropegia. The greatly enlarged Ceropegia 
based on this phylogenetic reconstruction now holds Brachystelma and all genera of the Stapeliads. Unfortunately, many new combinations, transferring Brachystelma species into Ceropegia, have been published even for Indian species without any insight into them ${ }^{49}$. Many distinct species such as B. maculatum, B. nallamalayanum, $B$. penchalakonense and the less known $B$. rangacharii have been synonymized under Ceropegia bourneae (Gamble) Bruyns. If such a synonymy is accepted for whatever good reasons it had, it amounts to blinding ourselves to our species. The other combinations published concerning Indian species are Ceropegia elenaduensis (Sathyan.) Bruyns, C. glabra (Hook.f.) Bruyns, C. kolarensis (Arekal \& T.M. Ramakrishna) Bruyns, C. laevigata (Wight) Bruyns, C. mahajanii (Kambale \& S.R. Yadav) Bruyns, C. malwanensis (S.R. Yadav \& N.P. Singh) Bruyns, C. matthewiana (Bruyns \& Britto) Bruyns, C. rapinatiana (Britto \& Bruyns) Bruyns, C. saldanhae (Britto \& Bruyns) Bruyns, C. swarupa (Kishore \& Goyder) Bruyns and C. vartakii (Kambale \& S.R. Yadav) Bruyns. Once realized it is a freeway for combinations, numerous new combinations got published by taxonomists without knowing the materials fully and destroying the existing names. Kottaimuthu et al. ${ }^{50}$ published the combinations for the remaining recently described species ignoring even the synonymized species of Bruyns (2017). These include Ceropegia ananthapuramense (K. Prasad, A. Naray. \& Meve) Kottaim., C. annamacharyae (K. Prasad, Prasanna, Meve, Sankara Rao \& Thulasaiah) Kottaim., $C$. gondwanensis (Govekar, Kahalkar \& Sardesai) Kottaim., C. gandhiana Kottaim. (=B. Maculatum Hook.f.), C. megamalayana (Karupp.) Kottaim., C. mahendragiriense (K. Prasad, Chorghe \& Venu) Kottaim., C. nallamalayanum (K. Prasad \& B.R.P. Rao) Kottaim., C. naorojii (P. Tetali, D.K. Kulk., S. Tetali \& Kumbhoj) Kottaim., $C$. nigidiana (Raja Kullayisw., Sandhyar. \& Pull.) Kottaim., C. penchalakonensis (Rasingam, Chorghe, Meve, Sankara Rao \& Prasanna) Kottaim., C. rangacharii (Gamble) Kottaim., C. seshachalamense (K. Prasad \& Prasanna) Kottaim., C. shrirangii (Kambale, Gholave \& Sardesai) Kottaim. and C. vemanae (A.M. Reddy, M.V.S. Babu \& K. Prasad) Kottaim. Such mechanical transfers only add up 'name noise' to the literature, and truly ignore the very ethics and stability of names concerning Indian Brachystelma. The intention of such publications is to take away the authority of names through this conventional and accepted bypass and get credit for 'discoveries' that were never made ${ }^{51}$.

The article has dealt with various issues concerning taxonomy practices in floral documentation. It has deliberated on lapses in reporting of new species, rediscoveries, new combinations, and designation of lectotypifications, without having a grasp on the genera concerned. It has also deliberated on problems in assigning threat status to species with limited knowledge on distribution. The article has explained that there are effective taxonomic practices and well-established methods which should not be ignored while publishing such reports. Their noncom- pliance by taxonomists and repercussions there on literature were presented with examples. The article has argued for greater caution, focused field works and fresh collections while building revised floras.

1. Thothathri, K. and Das, D., A new Annonaceae from the Andaman Islands. J. Bombay Nat. Hist. Soc., 1968, 54(3), 430-431.

2. Venkat Ramana, M. et al., The less known Mitrephora andamanica (Annonaceae) from Andaman Islands. Rheedea, 2015, 25(1), $72-76$.

3. Khandal, D. et al., Ceropegia lucida - rediscovery and new distribution record for Arunachal Pradesh, India. Curr. Sci., 2017, 113(11), 2077

4. Shruti, K. et al., Rediscovery of Saussurea andryaloides (Asteraceae: Cardueae) from Uttarakhand, India. Rheedea, 2019, 29(1), 116-118.

5. Hooker, J. D., The Flora of British India, Vols 1-7, L. Reeve \& Co, London, pp. 1872-1890.

6. Gamble, J. S., Flora of the Presidency of Madras, Vols 1-3, West, Newman and Adlard, London, UK, pp. 1915-1936.

7. Cooke, T., The Flora of the Presidency of Bombay, Vols 1-2, Taylor and Francis, London, UK, 1903.

8. Prain, D., Bengal Plants, Vols 1-2, N W \& Company Printers \& Publishers, Calcutta, 1903.

9. Plant Discoveries, Botanical Survey of India, Kolkata, 2019.

10. Srivastava, R. C. et al., Angiosperms of India known only by type collection. J. Threat. Taxa, 2015, 7(8), 7465-7470.

11. Bandyopadhyay, S. et al., Are we following the Art.40.7 of the Code in letter and spirit? Phytotaxa, 2014, 163(4), 239-240.

12. Bandyopadhyay, S. et al., Names of new taxa published and types deposited - a case study. Ann. Plant Sci., 2016, 5(10), 14511457.

13. Bandyopadhyay, S. et al., Failings in holotype deposition of twelve plant names. Indian J. For., 2017, 39(4), 407.

14. Bandyopadhyay, S. et al., Names of new taxa published and types deposited - a second case study. Ann. Plant Sci., 2017, 6, 15851589.

15. Bandyopadhyay, S. et al., Missing holotypes of names in plants, fungi and algae published from India. Int. J. Adv. Res. Bot., 2017, 3(3), 34-39.

16. Srivastava, R. C., A new species of Indian Cycas L. Indian J. Plant Sci., 2014, 3(1), 109-110.

17. Srivastava, R. C. and Jana, B., Cycas darshii RC. Srivast. \& B Jana sp. nova. Indian J. Plant Sci., 2014, 3(2), 151-153.

18. Srivastava, R. C. and Singh, L., A new species of Indian Cycas L. Int. J. Curr. Res. Biosci. Plant Biol., 2015, 2(8), 35-37.

19. Turland, N. J. et al., International Code of Nomenclature for algae, fungi, and plants (Shenzhen Code) adopted by the Nineteenth International Botanical Congress Shenzhen, China, July 2017. Regnum Veg., 2018, 159. Koeltz Botanical Books, Glashütten, Germany.

20. Anon., Biological Diversity Act, 2002 and Biological Diversity Rules, National Biodiversity Authority, Chennai, 2004; www.nbaindia.org

21. Prasad, V. P., On a 17 th Century herbarium specimen and an archival letter in CAL. Nelumbo, 2014, 56, 255-258.

22. Prathapan, K. D. et al., Death sentence on taxonomy in India. Curr. Sci., 2008, 94(2), 170-171.

23. Venu, P. and Sanjappa, M., How accomplished are we for writing our national flora? Curr. Sci., 2019, 116(8), 1299-1303.

24. Sanjappa, M. and Venu, P., Indian herbaria: legacy, floristic documentation and issues of maintenance. In Proceedings on Tropical Plant Collections Legacies from the Past? Essential tools for the Future? (eds Fries, I. and Balslev, H.), The Royal Danish Academy of Sciences and Letters, Denmark, 2017, pp. 149-162. 
25. Vijaya Sankar, R. et al., Endemic species, Brachystelma brevitubulatum (Bedd.) Gamble (Asclepiadaceae), relocated after a century. Phytotaxonomy, 2003, 3, 130-133.

26. Kumar, A. and Amaduddin, M., Rediscovery of an endemic and endangered plant (Begonia tessaricarrpa C.B. Clarke) from Arunachal Pradesh, India, after a century. Curr. Sci., 2006, 91(8), 997-998.

27. IUCN Standards and Petitions Subcommittee 2019. Guidelines for using the IUCN Red List Categories and Criteria, Version 14. Prepared by the Standards and Petitions Subcommittee of the IUCN Species Survival Commission, 2019; http://jr.iucnredlist.org/ documents/RedListGuidelines.pdf (accessed on August 2019).

28. Jain, S. K. and Rao, R. R. (eds), An Assessment of Threatened Plants of India, Botanical Survey of India, Howrah, 1983.

29. Nayar, M. P. and Sastry, A. R. K. (eds), Red Data Book of Indian Plants - Vols I-III, Botanical Survey of India, Calcutta, 19871990.

30. Ganeshaíah, K. N., We need taxonomists not taxa-namists. Curr. Sci., 1998, 75, 412 .

31. Kumar, A., Biswamoyopteris biswasi (Saha 1981) or Ichthyophis tricolor (Annandale 1909)? Curr. Sci., 1998, 75, 426-427.

32. Ganesan, R., More on 'taxanamists'. Curr. Sci., 1998, 75, 1103.

33. Janarthanan, M. K., In defence of 'taxanamists'. Curr. Sci., 1998, 75, 1103-1104.

34. Hajra, P. K. et al., Hoshiarpuria minutiflora (Scrophulariaceae): a new genus and species from Punjab, India. Kew Bull., 1985, 40(3), 607-608.

35. Philcox, D., Hoshiarpuria Debunked. Kew Bull., 1986, 41(2), 432.

36. Hajra, P. K. et al., Hoshiarpuria minutiflora Hajra et al. in Kew Bull., 1985, 40(3), 607-608; A correction. Indian J. For., 1985, 8(2), 159.

37. van Steenis, C. G. G. J., Papilionopsis Steenis. Nova Guinea Bot., 1960, 3, 17.

38. Verdcourt, B., The identity of Papilionopsis stylidioides (Leguminosee). Kew Bull., 1977, 31(4), 845-846.

39. Rasingam, L. et al., Crotalaria nallamalayana (Fabaceae: Crotalarieae): a new species from Telangana, India. Phytotaxa, 2018, 345(2), 159-164.
40. Ravi Kiran, A. and Singh, R. K., On the identity of Crotalaria nallamalayana Rasingam \& J. Swamy (Fabaceae). Phytotaxa, 2018, 374(2), 177.

41. Ellis, J. L., Andrographis nallamalayana Ellis - a new species from Andhra Pradesh, South India. Bull. Bot. Surv. India, 1967, 8, 362 .

42. Gnanasekaran, G. et al., Andrographis nallamalayana, a heterotypic synonym of a little-known endemic species $A$. beddomei (Acanthaceae). Rheedea, 2015, 25(1), 47-53.

43. Hajra, P. K. et al. (eds), Flora of India Vol. 13, Asteraceae: Inuleae-Vernonieae, Botanical Survey of India, Calcutta, 1993.

44. Robinson, H. and Skvarla, J., Studies on the Paleotropical Vernonieae (Asteraceae): additions to the genus Acilepis from southern Asia. Proc. Biol. Soc. Wash., 2009, 122(2), 131-145.

45. Pramanik, A. and Gangopadhyay, M., Flora of India Vol. 1, Menispermaceae (eds Balakrishnan, N. P. and Hajra, P. K.), Botanical Survey of India, Calcutta, 1993.

46. Balakrishnan, N. P. and Chakrabarty, T., The Family Euphorbiaceae in India: A Synopsis of its Profile, Taxonomy and Bibliography, Bishen Singh Mahendra Pal Singh, Dehra Dun, 2007, ISBN: 81-211-0579-X.

47. Venkat Ramana, M. et al., Name confusions in Indian cycads. Curr. Sci., 2018, 114(2), 269-272.

48. Singh, R. K. and Garg, A., Floristic Diversity of Valmiki Tiger Reserve, West Champaran District, Bihar, Today and Tomorrow's Printers and Publishers, New Delhi, 2020, ISBN 9978170196747.

49. Bruyns, P. V. et al., A revised, phylogenetically-based concept of Ceropegia (Apocynaceae). S. Afr. J. Bot., 2017, 112, 399-436.

50. Kottaimuthu, R. et al., Some new combinations and new names for flora of India. Int. J. Curr. Res. Biosci. Plant Biol., 2019, 6(10), 33-46.

51. Prasad, K. and Venu, P., A Taxonomic Revision of the Genus Brachystelma R. Br. in India, Bishen Singh Mahendra Pal Singh, Dehradun, 2020.

Received 28 September 2020; accepted 4 December 2020

doi: $10.18520 / \mathrm{cs} / \mathrm{v} 120 / \mathrm{i} 7 / 1152-1159$ 